\title{
A review of wave climate and prediction along the Spanish Mediterranean coast
}

\author{
A. Sánchez-Arcilla ${ }^{1}$, D. González-Marco ${ }^{1}$, and R. Bolaños ${ }^{2}$ \\ ${ }^{1}$ Laboratori d'Enginyeria Marítima (LIM/UPC), Universitat Politècnica de Catalunya, Barcelona, Spain \\ ${ }^{2}$ Proudman Oceanographic Laboratory (POL), Natural Environment Research Council, Liverpool, UK
}

Received: 7 May 2008 - Revised: 1 August 2008 - Accepted: 2 August 2008 - Published: 13 November 2008

\begin{abstract}
This paper reviews the characterization of wave storms along the Spanish/Catalan Mediterranean coast. It considers the "physical" and "statistical" description of wave parameters and how they are affected by the prevailing meteo patterns and the sharp gradients in orography and bathymetry. The available field data and numerically simulated wave fields are discussed from this perspective. The resulting limits in accuracy and predictability are illustrated with specific examples. This allows deriving some conclusions for both short-term operational predictions and a longterm climatic assessment.
\end{abstract}

\section{Introduction}

Wave climate is of paramount importance for coastal and offshore activities. It also plays a key role in determining coastal and naval hazards and in the associated management decisions. This is particularly true for coastal stretches such as the Spanish Mediterranean where the number of uses and resources supported by a limited territory require an accurate prediction of meteo-oceanographic conditions and climatic variability.

The NW Mediterranean climate is, however, difficult to forecast for time-horizons above 3 days. This is due to sharp gradients in space and time (see e.g. Bolaños et al., 2006) associated to mountain chains like the Pirinees or the Alps and to the abrupt coastal orography. The wind channelling due to river valleys and the abundance of submarine canyons plus a continental shelf with variable widths further illustrate this issue.

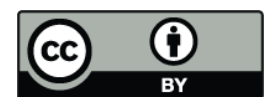

Correspondence to: A. Sánchez-Arcilla (agustin.arcilla@upc.edu)
Within the last decades the NW Mediterranean has experienced severe storm events characterised by (comparatively to other periods) large waves and winds. This has encouraged the interest of scientists, managers and stakeholders alike on such episodic events (Puig et al., 2001; Grémere et al., 2003; Skliris et al., 2004; Gómez et al., 2005) and their effects on physical, ecological and economic variables.

The short duration wind-storms, with veering winds and short fetches plus the shadow effect of islands and coastal capes pose a serious scientific and practical challenge which leads to "errors" in met-oceanographic conditions well in excess of those found for open sea domains (Cavaleri and Bertotti, 2003, 2004).

These "errors" limit the predictability to a few days and complicate the assessment of climatic trends and variability, which because of the relative short time-series of instrumental observations available, require hind-casted fields with an accuracy level not easy to achieve with present technology.

In summary, the characterization of wave storms in the NW Mediterranean, which follow the torrential pattern of meteo conditions (Gómez et al., 2005), is still achieved with significant levels of uncertainty. This affects operational predictions but also the long-term and extreme probabilistic distributions of wave variables. This paper will consider the "physical" and "statistical" characterization of wave conditions along the Northern Spanish Mediterranean coast. The emphasis will be on the meteo-oceanographic work done at the first author's institution together with the Catalan Meteorological Service. The main features of the considered coastal stretch (the Catalan coast) will be presented in Sect. 2. The driving meteo patterns will be treated in Sect. 3 .

Available field observations, from the local and central Government networks will be summarized in Sect. 4. The characterization, in physical and statistical terms, of episodic storm events will be the core of Sect. 5. Section 6 will briefly consider the implications for wave forecasting. 


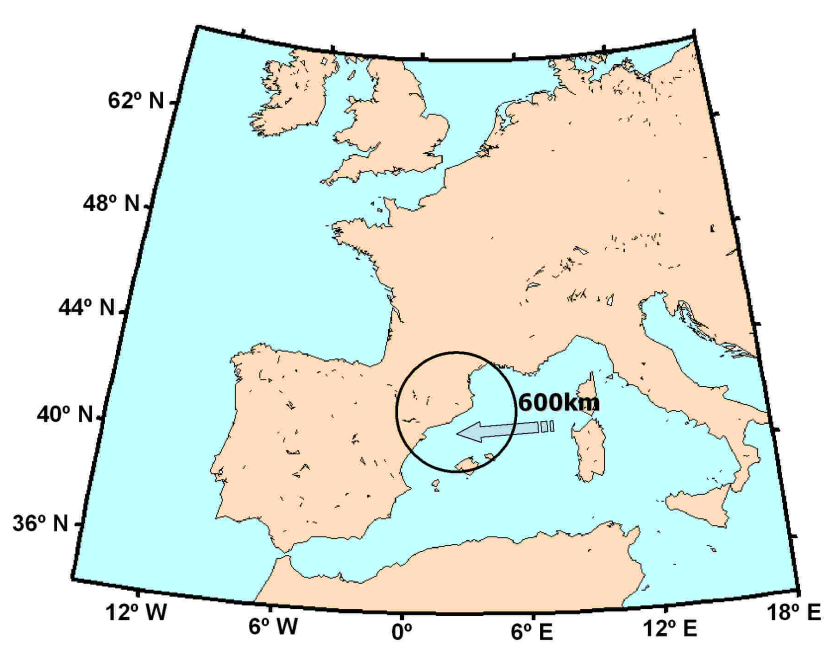

Fig. 1. The Catalan coast in the NW Mediterranean (black circle) and the maximum fetch for the prevailing wave storm direction.

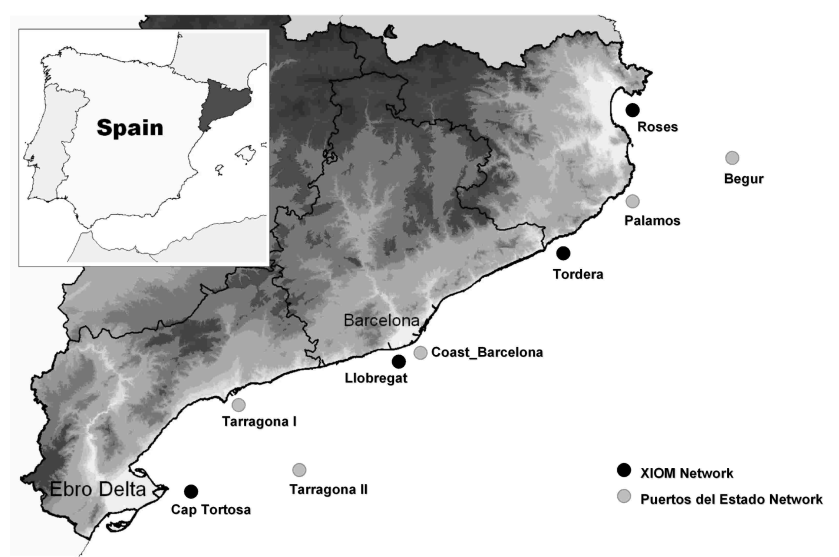

Fig. 2. Catalan coast and location of all buoys belonging to both networks, the XIOM (Catalan Regional Government) and Puertos del Estado (Spanish Government).

The implications of such storms and their associated uncertainties will be discussed in Sect. 7. The focus will be on coastal implications and how the hydro-morphodynamic interactions condition wave predictions. The paper will end (Sect. 8) with some conclusions for both short-term operational predictions and long-term climatic assessment.

\section{Study area}

The Catalan coast (see Figs. 1 and 2) is located in the NW Mediterranean, south of the Pirinees. The Catalan Sea, bounded by this coast and the Balearic islands (Fig. 2) lies below the Alps and the southern coast of France. The local topography exerts a significant control over wind climate which is characterised by low to medium average winds.

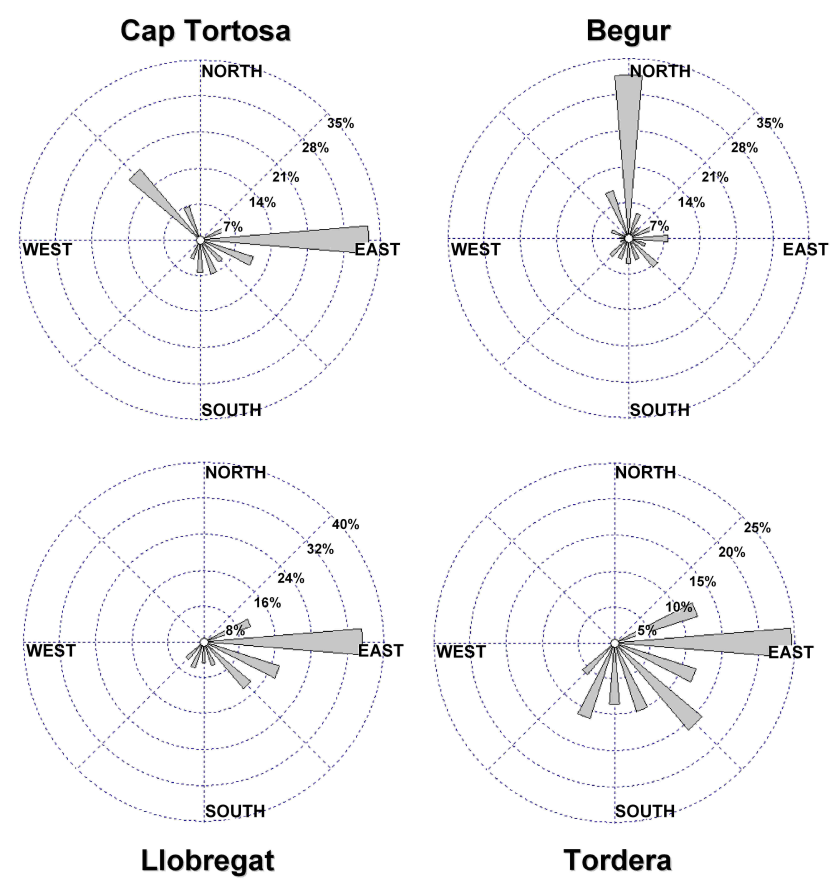

Fig. 3. Directional wave distributions along the Catalan coast. The radial axis indicates frequencies of occurrence. The upper left rose corresponds to the southern-most position. We go then towards the north in an anti-clock wise rotation, with the upper right figure corresponding to the northern-most position.

However some events (synoptic ones) are responsible for strong winds and gales in the Catalan and Balearic Seas.

The directional distribution of waves along the coast (Fig. 3) show a predominance of NW and $\mathrm{N}$ wave conditions at the southern and northern sections of the coast. The central part of the coast is dominated by $\mathrm{E}$ and $\mathrm{S}$ wave conditions. The largest waves come from the $\mathrm{E}$ or E-NE, where the largest fetches and stronger winds coincide.

The resulting wave fields show the gradients in wind fields due to topographic constraints and the short duration events associated to the meteorology of the area (see next section). These wave fields are further modified by the irregular bathymetry of the zone where submarine canyons, islands and capes produce "unexpected" variations in wave recordings a few kilometers apart (González-Marco et al., 2004).

These meteo-oceanographic factors act on a highly squeezed coast, bounded by a coastal mountain range and intersecting rivers (the city of Barcelona in between two such rivers is a good example), which requires a prediction of wave conditions along the coast at a level well above what is offered by the present state-of-art. 


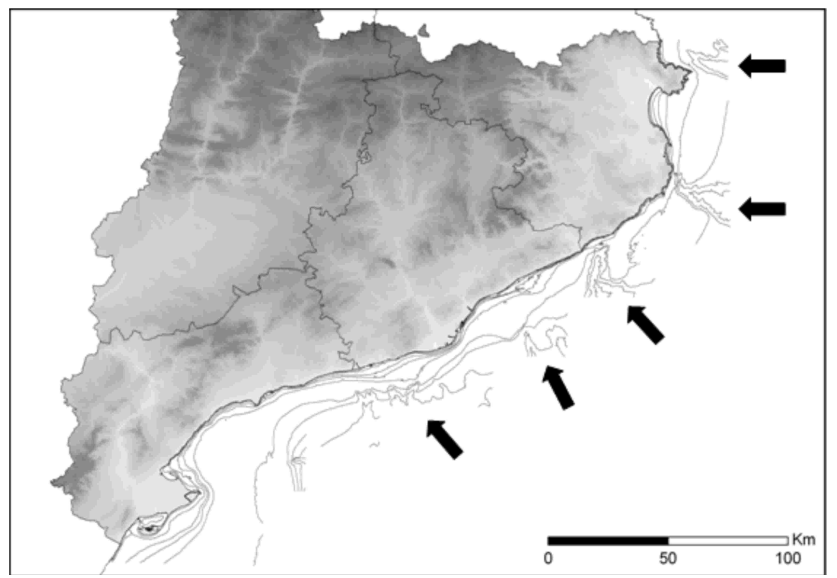

Fig. 4. Catalan coast showing orography in grey scale and bathymetric contours. The arrows indicate submarine canyons (and thus, regions of sharp bathymetry gradients).

\section{Meteo-oceanographic patterns}

The meteorological patterns over the NW Mediterranean exhibit sharp gradients associated to the topographic control on synoptic fluxes (Wallen, 1970; Martin-Vide and Olcina, 2001). This area, covering from $-5^{\circ} \mathrm{E}$ to $16^{\circ} \mathrm{E}$ longitude and from $35^{\circ} \mathrm{N}$ to $44^{\circ} \mathrm{N}$ latitude (Fig. 1) is located between Spain, Southern France, Italy and Gibraltar/Northern Africa.

The orographic control plus an important cyclogenesis tendency result in a torrential climate both for wind and wave conditions (Gómez et al., 2005).

The predominant winds come from the North and Northwest, primarily during December and January. Southerly and Easterly winds are also important particularly during the months of February, March, April and November (Del Amo, 2000).

At the Catalan coast (Fig. 4b), as it was mentioned before, the local topography exerts a significant control over the wind climate which is characterised by low average winds. However some events, especially synoptic ones, are responsible for strong winds and gales in the Catalan Sea. In general, four predominant wind directions can be found in this area: NE, E, SW and NW. The maximum velocities have been recorded from Eastern winds in agreement with storm conditions associated with cyclonic activity over the NW Mediterranean (Del Amo, 2000). A particular region within this coast is the Ebre Delta (Fig. 4b), where NW winds funnelled through the Ebre river valley are the most typical. These offshore winds result in a fetch and duration limited wave climate where eastern waves have a maximum fetch below approximately $700 \mathrm{~km}$. As a result of this, only relatively small waves should be expected.

The predominant wind and wave directions vary along the coast, showing clearly the topographic control. When comparing (Fig. 5) the directional distributions of wind and
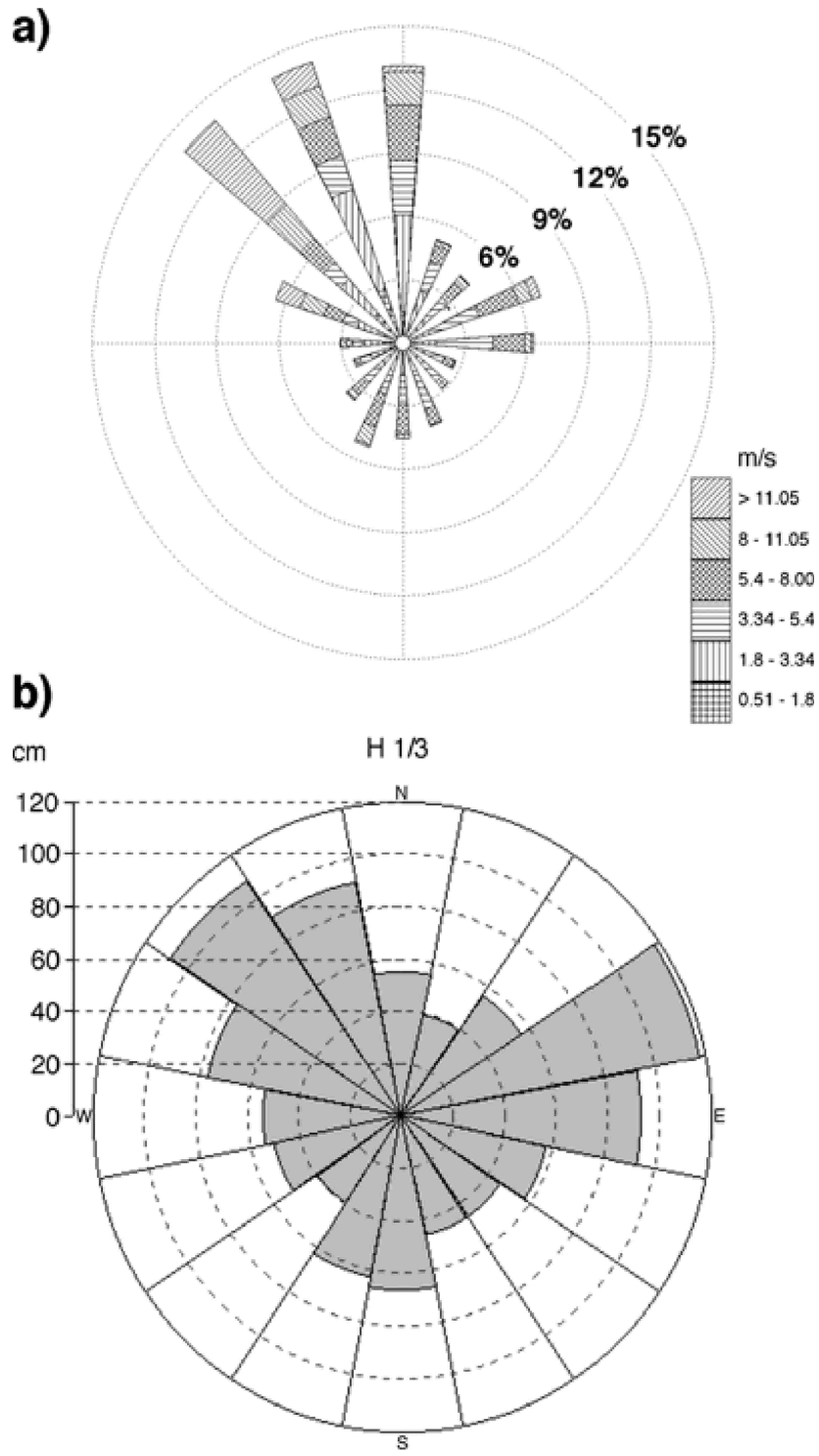

Fig. 5. Rose diagrams showing: (a) $10 \mathrm{~m}$ wind speed and directions at the Ebre Delta meteo-station (1997-2002). (b) Mean significant wave heights and directions off the Ebre Delta position (1995-2002). Both refer to incoming directions (after Bolaños et al., 2007).

waves off the Ebre Delta coast (the southern most station in Fig. 2) it is apparent that the largest number of observations occur from the North-Northwest, although large wind speeds can also be found for East and South events. Therefore, the typical local wave climate shows a predominance of NW conditions, with significant East and South storms. These storms show a large variability in wind fields and tend to develop a large amount of bimodal spectra due to the coexistence of sea and swell waves (Bolaños et al., 2007).

It should also be mentioned that sea/swell definitions depart from open sea conditions. Swell waves (i.e. waves 


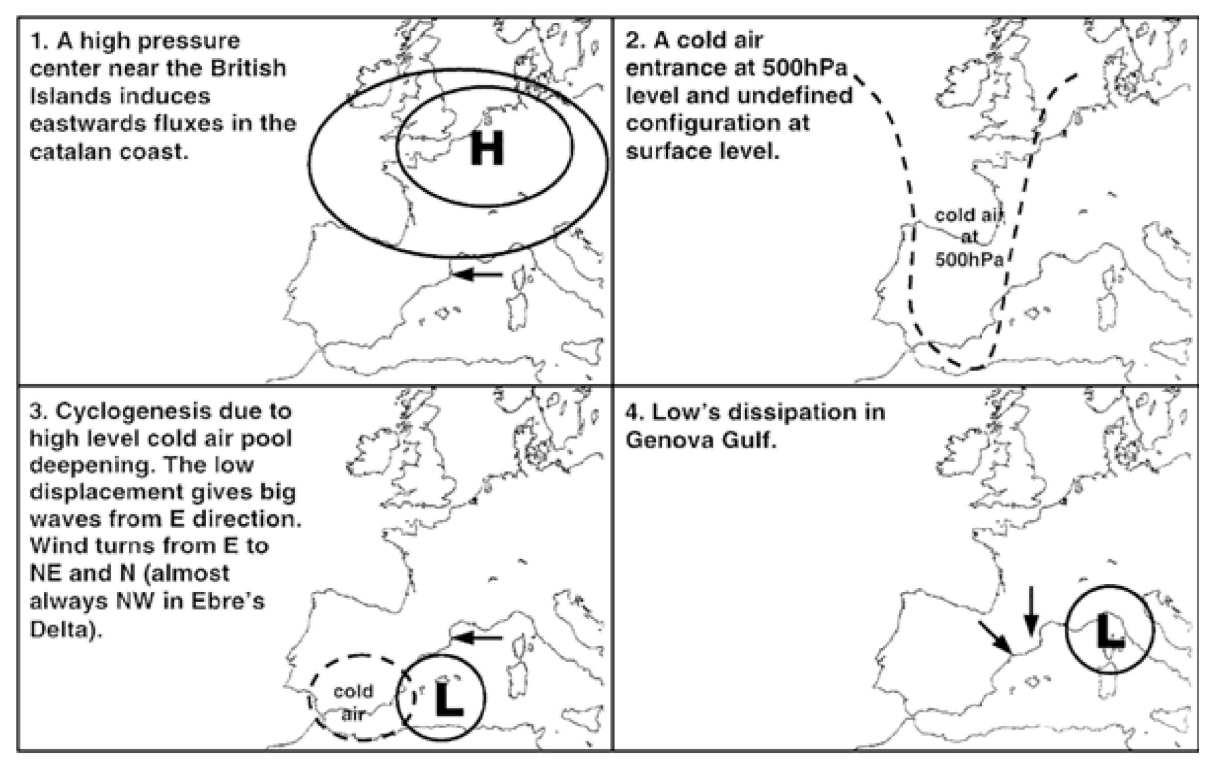

Fig. 6. Synoptic representation of a NW Mediterranean wave storm during its main evolution stages (after Bolaños et al., 2007).

outside the generation area) start at periods of about $7 \mathrm{~s}$ and seldom ago above $12 \mathrm{~s}$. García et al. (1993) found that swell, with criteria of $\varepsilon<0.3$ and $H s / L<0.01$ (narrow spectrum and not very steep waves,) would be unlikely to occur along the Ebre Delta coast where most of the observed storm spectra were broad banded ( $\left.\varepsilon_{4} \approx 0.7-0.8\right)$, in which $H_{S}$ stands for significant wave height $L$ is the wave length associated to the spectral peak and the spectral width $\varepsilon_{4}$ is defined by

$\varepsilon_{4}=\left[1-\left(m_{2}^{2} / m_{0} M_{4}\right)\right]^{1 / 2}$

$M_{n}=\int_{0}^{\infty} f^{n} E \partial f$

Typical wave storms can be illustrated by the sequence of meteorological patterns shown in Fig. 6 (after Bolaños et al., 2007). This sequence corresponds to the November 2001 storm, one of the most devastating ones along the Catalan coast, with significant damages to coastal/harbour infrastructures and neighbouring beaches. On 10 November 2001, a low pressure system appeared over the NW Mediterranean while a high pressure centre was located in the NE Atlantic. On 11 November pressure gradients increased producing the first storm peak. Subsequently, the system relaxed until the 15 th when another low pressure system was generated over the NW Mediterranean. This produced the second storm peak recorded by the buoys.

The storm evolution could also be studied from the coexisting time-series of wind and wave data. This exercise has been done for the wave buoy off the Ebre Delta coast and for a number of meteorological stations deployed at or near the Delta (in-land stations). The rest of wave buoys recording along the Catalan coast have also been considered. The most severe storm featured strong winds of up to $18 \mathrm{~m} / \mathrm{s}$ measured at the Ebre Delta. Significant wave heights reached $6 \mathrm{~m}$ at this location and about $4.5 \mathrm{~m}$ were recorded by the other buoys. Along the coast the buoys recorded two peaks of significant wave height $(H s)$ with a gap of 4 days in between. Mean periods $\left(T_{Z}=\sqrt{m_{0} / m_{2}}\right)$ up to $9 \mathrm{~s}$ were registered and the wave direction had a main Eastern component. A classification of the recorded spectra has already been performed considering the number of spectral peaks, predominance of sea or swell and the existence of a sea peak with one or more swell peaks (Bolaños et al., 2005).

\section{Available data}

The Catalan Coast is one of the most heavily instrumented coastal areas along the Spanish Mediterranean which allows obtaining good estimations of the wave climate characteristics. Along the $700 \mathrm{~km}$ of Catalan Coast, there are 9 buoys deployed at different depths (ranging from 35 to $1200 \mathrm{~m}$ depth), belonging to two different networks, the XIOM network (belonging to the Catalan regional Government) (Bolaños et al., 2008) and the Puertos del Estado network (belonging to the Spanish Government). Most of the analysis will be carried out with data from the first network although a number of inter-comparisons will be also included.

The XIOM network (Xarxa d'Instrumentació Oceanogràfica I Meteorològica) for oceanographic and coastal meteorological measurements is owned by the Catalan autonomous government. In terms of oceanographic instruments, the XIOM network is composed by 4 wave buoys deployed along the Catalan Coast (see Fig. 2) at 
Table 1. Summary of the main deployment characteristics from the two wave buoy networks along the Catalan (Spanish Mediterranean) Coast.

\begin{tabular}{|c|c|c|c|c|c|}
\hline & Buoy & Type & Start date & Depth (m) & Available Data \\
\hline $\mathrm{X}$ & Cap Tortosa & Directional & 1990 & 60 & Wave Statistics and Directional \\
\hline I & & & & & Spectra \\
\hline \multirow{2}{*}{$\mathrm{O}$} & Llobregat & Scalar / Directional & 1984 & 45 & Wave statistics and Directional \\
\hline & & & & & Spectra \\
\hline \multirow[t]{4}{*}{ M } & & & & & \\
\hline & Tordera & Scalar / Directional & 1984 & 75 & Wave statistics and Directional \\
\hline & & & & & Spectra \\
\hline & Roses & Scalar & 1992 & 45 & Wave statistics and Spectra \\
\hline P E & Tarragona I & Scalar & 1992 & 35 & Wave statistics and Spectra \\
\hline U S & Tarragona II & Directional & 2006 & 672 & Wave statistics and Directional \\
\hline $\mathrm{E} \mathrm{T}$ & & & & & Spectra \\
\hline \multirow[t]{2}{*}{$\mathrm{R} A$} & Coast_Barcelona & Directional & 2004 & 68 & Wave statistics and Directional \\
\hline & & & & & Spectra \\
\hline \multirow[t]{2}{*}{$\mathrm{T} \mathrm{D}$} & & & & & \\
\hline & Palamos & Scalar & 1988 & 90 & Wave statistics and Spectra \\
\hline $\mathrm{OO}$ & Begur & Directional & 2001 & 1200 & Wave statistics and Directional \\
\hline S A & & & & & Spectra \\
\hline
\end{tabular}

depths ranging from 45 to $75 \mathrm{~m}$ depth. This network, which is used for operational wave and meteorological purposes, starts in 1984 when two scalar buoys were deployed in front of the most vulnerable regions close to Barcelona (Llobregat delta) and Blanes (Tordera delta). In 1990, the constant retreat of the coastline at the Ebre Delta (the main deltaic formation in the Mediterranean Spanish Coast) motivates the deployment of a directional buoy in this region (in front of the Tortosa Cape). Finally, in 1992 a scalar wave buoy was deployed in the Roses bay. In 2004 the Llobregat buoy was replaced by a directional one, as well as the Tordera buoy in 2007. Figure 2 shows the actual position of these buoys, and Table 1 describes their main characteristics and available data. A more detailed description of the XIOM network can be found in Bolaños et al. (2008).

The Puertos del Estado network, also for oceanographic and coastal meteorological measurements, is owned by the Spanish Ministry of Public Works of the Spanish Government. At the Catalan coast (see Fig. 2) it has two deep water buoys: Tarragona II (672 m depth starting in August 2006) and Begur (1200 m depth, starting in March 2001) recording conventional ocean and atmospheric variables (wave spectra, wind velocity, direction, atmospheric pressure, current speed and direction). There are also, in this network, three coastal wave buoys: Tarragona I (35 m depth, starting in 1992), Coast_Barcelona (68 m depth, starting in March 2004) and Palamos (90 m depth starting in 1988). Table 1 summarises their main characteristics and data available.

\section{Wave conditions}

\subsection{Mean wave climate}

The Catalan coast, located in the NW Mediterranean has thus some special features that determine the wave climate:

- Short fetches. The presence of the Balearic Islands, Sardinia, Corsica and even Sicily reduces fetch. The maximum fetch is about $600 \mathrm{~km}$ from the East

- Shadow effect for waves from the South and East due to the Balearic islands

- Complex bathymetry with deep canyons close to the coast

- High wind field variability in time and space 
Table 2. Results of the extreme analysis, in terms of return periods, of the XIOM wave buoy data (after Bolaños et al., 2008).

\begin{tabular}{lllllll}
\hline & \multicolumn{7}{c}{ Return Period (years) } \\
XIOM Buoys & 5 & 10 & 25 & 50 & 100 & 500 \\
\hline Cap Tortosa $-H s(\mathrm{~m})$ & 4.6 & 5.1 & 5.7 & 6.1 & 6.6 & 7.6 \\
Llobregat $-H s(\mathrm{~m})$ & 4.0 & 4.3 & 4.8 & 5.1 & 5.4 & 6.1 \\
Tordera $-H s(\mathrm{~m})$ & 4.5 & 5.0 & 5.5 & 5.9 & 6.3 & 7.2 \\
Roses $-H s(\mathrm{~m})$ & 5.3 & 6.0 & 6.9 & 7.5 & 8.1 & 9.5 \\
\hline
\end{tabular}

- Wave calms during the summer and energetic storms from October to May.

These conditions induce a complex wave climate, which can be described as "Torrential". By this concept we mean a predominance of "impulsive" and discontinuous wave storms comparatively much more energetic than adjacent calm periods which occur most of the time (in this sense it would be the equivalent of torrential rains in meteorology or torrential creeks in geography). Wave storms along this coast are limited due to short fetches of less than $600 \mathrm{~km}$ and storm durations of an average less than $24 \mathrm{~h}$, plus complex topobathymetric features. This results in mixed sea states formed by wave trains with more than one mean direction and more than one peak frequency with a yearly average between 0.6 (Roses) and 0.8 (Cap Tortosa) meters for the coastal locations and above $1 \mathrm{~m}$ for deeper water (more exposed) buoys (e.g. Begur or Tarragona II locations, see Fig. 2). The average number of storms per year also varies from about 5 for the coastal buoys to more than 10 for the exposed buoys (including the Cap Tortosa buoy, which is highly influenced by land winds). The relatively small number of storms registered hinders the assessment of extreme events which feature, nevertheless, storm peaks with $H_{s}$ between 5 and $7 \mathrm{~m}$ (Gómez Aguar et al., 2005). These energetic events are concentrated in two periods, namely during October-December and March-April. The recommended threshold value for the significant wave height (to define the storm events considered in the statistics) goes from $1.5 \mathrm{~m}$ to $2.0 \mathrm{~m}$ (e.g. Puertos del Estado, 1994).

As it has been mentioned, Fig. 3 shows a rose diagram of the Tortosa, Llobregat, Tordera and Begur Buoys. It is evident the relevance of the NW component at Tortosa, which turns into a $\mathrm{N}$ component at Begur, while in Llobregat and Tordera waves are limited to the E and S sectors. These sectors, here and throughout the paper, refer always to the direction from which the waves are coming, as it is usually done in wave studies.

\subsection{Extreme wave climate}

For an extreme analysis it is necessary to make some assumptions regarding storm events such as whether storms come from a single population (homogeneity), no climate change trends are present and the events are independent. For the definition of an independent storm event it is necessary a criterium of minimum significant wave height, interval without data, period with data below the minimum significant wave height and minimum duration. To derive an extreme sample the peaks over a threshold (POT), separated by four days or more (to achieve a certain degree of statistical independence), have been selected. The criteria to define a storm sample have, thus, been i) the distance between storm (consecutive) down-crossing and up-crossing being larger than four days, ii) the eventual periods below the threshold level being smaller than six hours. For the strongest events their association to a single low-pressure centre was also considered. The resulting sample showed a differential behaviour in terms of wave height and wave period and storm duration when considering the main three sectors of wave incidence (East, South and North-West). This suggest a directionalbased analysis to improve the homogeneity of the resulting sub-samples. This exercise could not be completed with the available time series due to the small number of storms left in each directional sector.

The resulting "scalar" (i.e. for all directions) sample frequencies have been fitted to Gumbel, Frechet and Weibull distributions using a variety of techniques to estimate the corresponding parameters (method of moments, maximum likelihood and least squares). For the least squares method a number of plotting position formulae have been tested (Gómez Aguar et al., 2005). The confidence interval was determined using bootstrap simulations and standard recommendations for wave analyses (e.g. PIANC). The resulting best fit extreme distribution for $H s$ is the Weibull PDF. It is usually written within the maritime engineering community as:

$$
F(H s)=1-\exp \left[-\frac{H s-A}{B}\right]^{C}
$$

where $A$ is the location or position parameter, $B$ is the scale parameter and $C$ the shape parameter.

This distribution corresponds to a small number of relatively energetic events (corresponding to a semi-enclosed sea domain such as the NW Mediterranean). The threshold selected for defining a storm was $2 \mathrm{~m}$. It results in a poor characterization of the upper tail with e.g. an $\mathrm{Hs}$ of $10 \mathrm{~m}(95 \%$ confidence limit) for a return period of 300 years in Cap Tortosa (see Fig. 7 red lines). The maximum $H s$ ever recorded at this location, during an interval of 18 years, was $5.95 \mathrm{~m}$. Table 2 (after Bolaños et al., 2008) shows the resulting extreme analysis for the XIOM buoys in terms of the return period. The data show that the northern and southern (Tortosa and Rosas) locations are the ones presenting higher waves while the central part shows lower wave heights.

The extreme analysis for $H s$ can be also obtained applying the Bayesian Generalized Pareto Estimation (BGPE) approach. The BGPE method shows a narrower confidence 
interval. This method assumes that the peaks over a threshold fit a Generalized Pareto Distribution (GPD), which includes the Weibull, Frechet and Gumbel distributions as particular cases. The BGPE (Egozcue and Tolosana-Delgado, 2002) includes also prior information regarding the studied phenomenon. It may be based on physical knowledge, expert and professional experience, data from similar situations, etc. Typical examples of prior information used are:

- An improbable event size to be considered and its maximum frequency

- A characteristic event size and its maximum frequency

- A certainly attainable event size

This information is independent of the used data set and represents the "knowledge" before data acquisition. It is useful to reduce the uncertainty of the estimation delimiting the admissible domain of the Bayesian parameters.

Using as an example the Cap Tortosa buoy position, for establishing bounds in the proposed Bayesian approach, the prior information used is:

- An improbable storm peak "event size" and its maximum frequency were taken as $12 \mathrm{~m}$ and $10^{-5}$, respectively, derived as an $\mathrm{Hs}$ close to the double of the maximum peak ever recorded and requiring wind speeds extremely unlikely.

- A characteristic event size of $H s=2.7 \mathrm{~m}$ and its maximum frequency of $f=0.4$ derived from the available statistical analyses of wind and wave fields.

- A certainly attainable storm peak of $H s=6.5 \mathrm{~m}$ slightly above those actually recorded or numerically generated.

This information represents the prior available knowledge and may be derived from a complementary data set from the same wave buoy or from another one deployed at a point with "similar" wave climate. Although in part subjective, this prior information substantially reduces the uncertainty of the estimation, delimiting the admissible domain of Bayesian parameters. The obtained reduction in uncertainty is also consistent with available knowledge and observations on the local wave climate and its impact on coastal infrastructures. A comparison between both, the Classic and the Bayesian approaches can be seen in Fig. 7 (after Bolaños et al., 2008). This figure illustrates that the Bayesian approach reduces the values of $H s$ and the interval bounds, especially the upper one.

\section{Wave forecasting}

Operational wave forecasting in the NW Mediterranean requires a wind prediction system. The Meteorological Service

\section{Return Period of Hs in Cap Tortosa}

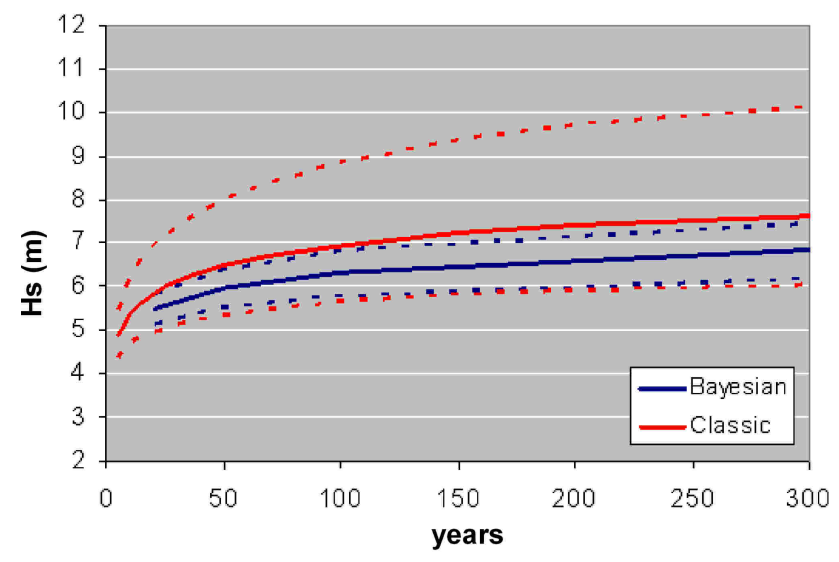

Fig. 7. Comparison of extreme distributions obtained with both approaches, the classic (red lines) and the BGPE (blue lines). Dashed lines represent the $90 \%$ confidence interval limits.

of Catalonia has implemented the MASS (Mesoescale Atmospheric Simulation System) (Codina et al., 1997; MESO, 1994) model to produce weather forecasts in the Catalan region. The model is based on a set of partial differential equations expressing the conservation of momentum, energy and mass. The model incorporates a high resolution Blackadar type planetary boundary layer parameterisation and detailed surface energy and moisture budget that include the parameterisation of surface hydrology and evaporation. The MASS model is a 3-dimensional hydrostatic primitive equations mesoscale model which is run with a horizontal grid resolution of $55 \mathrm{~km}$ covering the Mediterranean. A nesting strategy is applied for the Iberian peninsula with a resolution of $15 \mathrm{~km}$. This code is used as a general operational meteorological tool and as a tool to predict wind fields that are later used as an input for wave and current models (SánchezArcilla et al., 2002; Bolaños et al., 2008).

Wind-wave models are very sensitive to wind field variations which results in one of the main sources of error in wave forecasts. This is particularly true for the NW Mediterranean, which presents short fetches and duration limited events, leading to larger wave model errors compared with the open ocean case (Cavaleri and Bertotti, 2003, 2004). This is due to the large gradients and variability present in the wind/wave fields which lead to situations of veering winds. It is common in this area to have eastern or southern winds with co-existing north-west winds which "appear" in the records at periods when the first component slackens. The E/S winds blow from the sea and have comparatively much longer fetches than the NW winds which blow from land (the coast has an approximate NE-SW orientation) and have thus a very short fetch. This results in more robust predictions for eastern and southern waves while the accuracy rapidly degrades for NW waves close to the coast (where the buoys are deployed). For this 
Table 3. Errors in $H s$ predictions from the Catalan operational WAM (2000-2006) and for different forecast horizons. Units are in $\mathrm{cm}$ and the horizons in hours. Postitive values indicate model overestimation. Observe that the small bias value results from a compensation of positive and negative errors.

\begin{tabular}{lrrrrrr}
\hline$H s$ & \multicolumn{3}{c}{ Blanes } & \multicolumn{3}{c}{ Rosas } \\
\hline Horizon & +12 & +24 & +36 & +12 & +24 & +36 \\
Bias & -0.52 & 2.6 & 4 & -1.38 & 0.08 & -0.39 \\
RMSE & 51 & 66 & 73 & 39 & 39.6 & 51.6 \\
Scattering & 0.68 & 0.87 & 0.97 & 0.6 & 0.62 & 0.8 \\
\hline \multicolumn{3}{r}{ Tortosa } & \multicolumn{3}{c}{ Llobregat } \\
\hline Bias & -7.5 & -5.36 & -3.9 & 2.1 & 3.9 & 5.9 \\
RMSE & 37 & 56 & 57 & 36 & 35.5 & 54 \\
Scattering & 0.46 & 0.69 & 0.71 & 0.48 & 0.47 & 0.72 \\
\hline
\end{tabular}

reason, Bolaños et al. (2007) performed an evaluation of the modelled wind fields by a comparison to wind measurements (meteorological stations and satellite data) and their performance when simulating extreme wave events. For most of the coastal validation points the model predicted higher wind speeds than measured. Regarding wind direction, the model does not present large discrepances, although considerable differences with recorded data are found during some specific dates. There is a positive bias in the model, probably due to the local orography not resolved by the atmospheric code. The large scatter in the data shows that errors are not simply systematic and might vary under different environmental conditions. The negative bias of winds from MASS compared with QuikSCAT and the positive bias when comparing them with coastal stations have been linked to the effect of local (hundred of meters) orography on coastal stations which are missed by wind models. These errors, likely due to poor estimates of surface roughness over land (poorly resolved orography) and sea, get worse within the land sea border.

The wave forecast system at the Catalan coast is based on the WAM-P model (Monbailu et al., 2000). It runs twice daily with a forecasting horizon of $36 \mathrm{~h}$ and a wind field input every $6 \mathrm{~h}$. The geographical grid covers latitudes $34^{\circ} \mathrm{N}$ to $45^{\circ} \mathrm{N}$ and longitudes $5^{\circ} \mathrm{W}$ to $18^{\circ} \mathrm{E}$ and a resolution of $1 / 6^{\circ}$ (18 km approximately). The model is set to 24 directions and 25 frequencies. WAM-P is a widely known spectral wave model that solves the transport equation (WAMDI group, 1988; Komen et al., 1994) without any limitation on the wave energy spectral form. The main processes considered in this type of models are wind input, dissipation and non-linear wave interactions.

Bolaños et al. (2007) used WAM-P at the north-western Mediterranean to support the evaluation of two wind models when predicting severe wave storms. The analysed wave
Table 4. Errors in $T z$ predictions from the Catalan operational WAM (2000-2006) and for different forecast horizons. Units are in seconds and the horizons in hours. Postitive values indicate model overestimation.

\begin{tabular}{lrrrrrr}
\hline$T z$ & \multicolumn{3}{c}{ Blanes } & \multicolumn{3}{c}{ Rosas } \\
\hline Horizon & +12 & +24 & +36 & +12 & +24 & +36 \\
Bias & 0.69 & 0.82 & 0.85 & 0.78 & 0.85 & 0.82 \\
RMSE & 1.2 & 1.33 & 1.33 & 1.31 & 1.37 & 1.33 \\
Scattering & 0.3 & 0.32 & 0.32 & 0.35 & 0.36 & 0.35 \\
\hline & \multicolumn{3}{c}{ Tortosa } & \multicolumn{3}{c}{ Llobregat } \\
\hline Bias & 0.97 & 1.12 & 1.13 & 0.61 & 0.74 & 0.78 \\
RMSE & 1.32 & 1.46 & 1.47 & 1.11 & 1.18 & 1.20 \\
Scaterring & 0.35 & 0.39 & 0.39 & 0.26 & 0.28 & 0.28 \\
\hline
\end{tabular}

events show that the NW Mediterranean, in spite of its limited fetch, is able to generate harmful storms. The prediction of such storms near the coast is a tough challenge for operational oceanography. The wind interaction with local topography, the sharply varying fields, the resulting sea-swell interaction and the influence of the land-sea border explain this situation.

Operational validations of these models are being continuously carried out using the XIOM wave-buoy network. In Bolaños et al. (2008) and Bolaños et al. (2003) some general statistics of the system are presented. Table 3 shows the "lumped" statistics of significant wave height for the four wave buoy locations and three forecast horizons of the wave forecasting system. It is interesting to note the different behaviour for the various forecast horizons. The Blanes location is the only one showing the "expected" behaviour (i.e. decreasing quality with increasing forecast horizon) which agrees with its more "simple" geographical domain. This domain is not affected by mistral (NW) winds as is the case for the southern-most buoy (Tortosa). Moreover the spatial resolution of the model appears suitable for central locations such as Blanes, which is not the case for the northern catalan coast (Roses Bay) where the topographic irregularities require much higher resolutions. The overall statistics do not show a clear patter of overestimation or underestimation, since errors vary from location to location showing the importance of local effects.

Table 4 shows the corresponing statistics of mean period for the four wave buoy locations and three forecasting horizons. In contrast to $H s$ the mean period shows the expected reduction of prediction quality with forecasting horizon, increasing bias, RMSE and scatter. The Llobregat (central coast) location shows the best prediction for mean wave period. In all cases the dominant pattern is a model overestimation more evident in the Tortosa (southern coast) buoy. This 


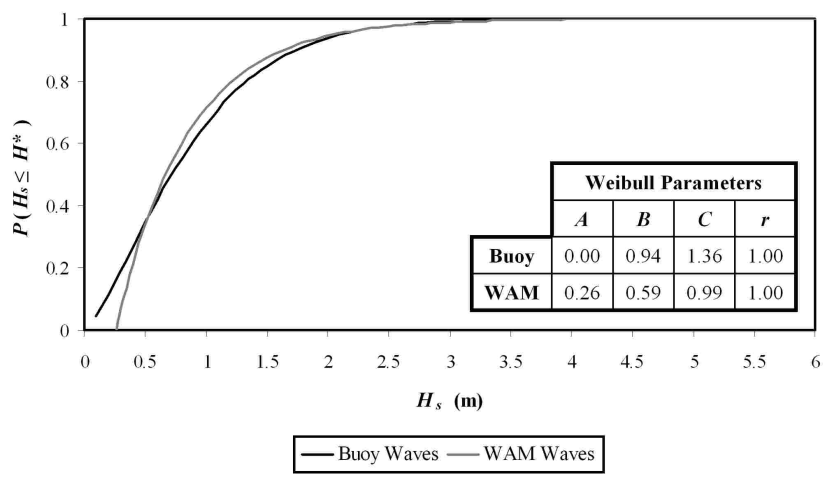

Fig. 8. Comparison of the probability distribution functions for the significant wave height off the Ebre Delta coast using measured (buoy) data and numerically simulated (WAM) data.

could be related to the "errors" during mistral events which produce high waves with low periods not so well predicted by present models.

The general sources of error for operational wave modelling along the Catalan coast have been discussed in Bolaños et al. (2004). Errors for low frequency swell at the buoy appeared to be mainly due to errors in the wind fields.

The spatial resolution is a very important source of error that affects both wind and wave models. At the buoy locations there are some local features that have considerable impact on wind patterns and, thus, also on waves. The wave model in our operational system is used with $6 \mathrm{~h}$ wind input. This configuration leads to a proper time definition of severe (large duration) storms at the Catalan coast, but may lead to information losses for NW storms which are characterized by severe winds but with a mean duration of less than $24 \mathrm{~h}$ with some cases of intense wind lasting only about $12 \mathrm{~h}$.

The occurrence of bimodal wave features may also have different implications (Bolaños et al., 2005, 2006): the first one is that, because of the spatial resolution, the local NW wind that produced the second peak of spectra is not well resolved. The second implication is related to momentum transfer, where many authors have highlighted that under mixed wave-train conditions the drag coefficient may increase appreciably. Additionally, Donelan (1987) and Mitsuyasu and Yoshida (1989) have shown a different wave growth rate in conditions of pre-existing swell. These conditions will produce errors on the predicted spectral shapes.

\section{Discussion}

The wave climate described above, has been obtained using measured data. However, when observational data are not available, numerical simulations must be used. This implies a larger degree of uncertainty, especially for a semi-enclosed sea such as the Mediterranean. The differences between mea-
Table 5. Summary of the comparison between cumulative probability for the significant wave height distribution derived from buoy data and from numerically simulated (WAM) data. Calm conditions have been taken at three levels while the mild storm conditions are typical of those events for the area. $H^{*}$ indicates the reference $H s$ level to characterize the scenario and to calculate the corresponding cumulative probabilities.

\begin{tabular}{lccc}
\hline $\begin{array}{l}\text { Climatic } \\
\text { Scenarion }\end{array}$ & $\begin{array}{c}H_{S} \\
(\mathrm{~m})\end{array}$ & $\begin{array}{c}\text { WAM } \\
P\left(H_{S} \leq H^{*}\right)\end{array}$ & $\begin{array}{c}\text { Buoy } \\
P\left(H_{S} \leq H^{*}\right)\end{array}$ \\
\hline Dead Calm & 0.30 & 0.07 & 0.19 \\
Average Calm & 0.50 & 0.34 & 0.35 \\
Yearly Calm & 0.85 & 0.63 & 0.58 \\
Mild Storm & 2.00 & 0.95 & 0.94 \\
Max. Recorded & 5.90 & 0.99 & 0.99 \\
\hline
\end{tabular}

surements and simulations may lead to different distribution functions and, thus, to variations in the corresponding parameters.

As it has been mentioned above, the WAM model (WAMDI Group, 1988) was adapted for real time forecasting along the Catalan coast. It was validated for the study area showing a root-mean-square error of about $10-15 \%$ in the yearly average significant wave height predictions (Bolaños et al., 2004; Bolaños and Sánchez-Arcilla, 2006), where the yearly average $H s$ ranges between 0.75 and $1 \mathrm{~m}$. This model provides wave fields every $6 \mathrm{~h}$ in terms of significant wave height $H_{s}$, peak period $T_{p}$, and peak direction $\theta$. A comparison between the cumulative probability distribution function for the $H_{s}$ off the Ebre River Delta from the WAM model for the period 2002-2005, and the neighboring Cap Tortosa buoy measurements is shown in Fig. 8, including the corresponding Weibull parameters.

Figure 8 shows a clear pattern between predicted and measured waves. For small values of $H_{s}$ (calm periods) the WAM model overestimates the significant wave height. However for values above $0.5 \mathrm{~m}$, the WAM model underestimates $H_{s}$. This pattern is also illustrated in Table 5 in which a comparison of the cumulative probability for different meteooceanographic conditions (calm, mild storm and maximum recorded value) is summarized.

This behaviour in the offshore wave heights implies large uncertainties for evaluating the corresponding PDF nearshore. This is illustrated in Fig. 9, in which the cumulative PDF of $H s$ at $2.5 \mathrm{~m}$ in front of the Ebre Delta is shown for both the buoy waves and the WAM waves corresponding to the conditions described in Table 5. The obtained Weibull parameters are summarized in Table 6 . It is also assumed that waves are coming from the east and that the probability of $H_{S}$ offshore remains constant through the propagation "space", and $H_{S}$ varies only due to the hydro-morphodynamic processes acting during wave propagation. 


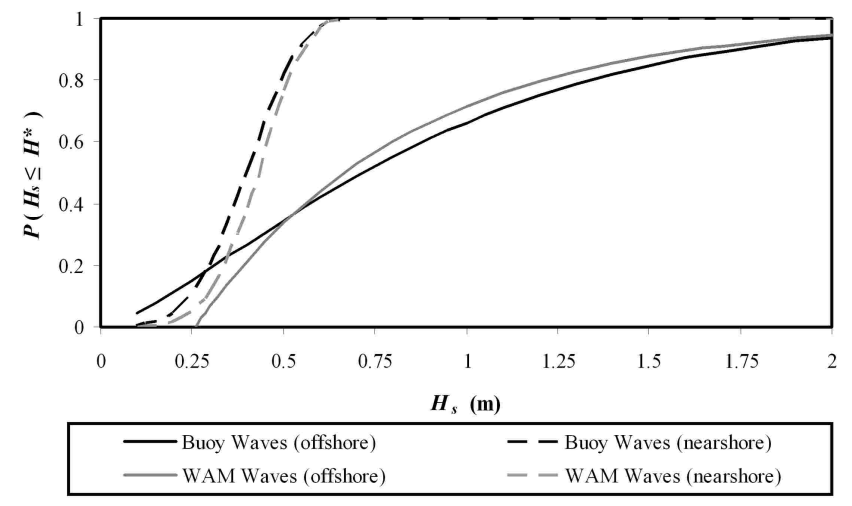

Fig. 9. Comparison of the significant wave height cumulative distribution functions derived from buoy and numerically simulated data at offshore and $2.5 \mathrm{~m}$ depth conditions.

The propagation from deep waters to the evaluation point has been done using the LIMWAVE numerical model (GonzálezMarco et al., 2004). The LIMWAVE is a phase-averaged code based on the conservation of the wave action equation (for the wave height), the eikonal equation (for the phase information) and the irrotationality of the wave number vector equation (for the wave angle) as described in Ebersole (1985) and Liu (1990). This model incorporates a depth-limited breaking dissipation according to Dally et al. (1985) for regular waves and according to Battjes and Janssen (1978) for irregular waves. Bottom friction dissipation was calculated using the expression of Tolman (1992) based on a quadratic friction law, with a friction factor proposed by Madsen et al. (1988), Nielsen (1992) or Madsen (1994).

This model therefore reproduces the more relevant processes affecting the wave propagation such as shoaling, refraction, diffraction, dissipation due to bottom friction and depth induced breaking. The LIMWAVE model takes into account the directional randomness via an a priori decomposition, the uncoupled propagation and the subsequent linear superposition starting from a Mitsuyasu directional spectrum (Mitsuyasu et al., 1975).

Figure 9 and Table 6 show that the nearshore $H s$ values obtained by propagating the offshore WAM waves are normally more narrowly distributed than "propagated" buoy (measured) data. This is illustrated by the shape parameter $C$, which is larger for WAM waves at the evaluation depth. However, the position and scale parameters $A$ and $B$ are similar. These results indicate that for a given probability level the WAM-based simulations provide slightly larger values of the wave height than those from buoy-based simulations.

These points should be carefully considered when selecting a modelling sequence for operational predictions or when suggesting (recommending) a distribution function for wave height under conditions like those of the Catalan coast.
Table 6. Summary of the 3 Weibull parameters and the corresponding correlation coefficient for the wave height distribution functions shown in Fig. 9.

\begin{tabular}{lrrrr}
\hline & \multicolumn{4}{c}{ Weibull Parameters } \\
\hline & A & B & C & r \\
\hline Buoy offshore & 0.00 & 0.94 & 1.36 & 1.00 \\
WAM offshore & 0.26 & 0.59 & 0.99 & 1.00 \\
Buoy nearshore & 0.00 & 0.47 & 3.99 & 0.93 \\
WAM nearshore & 0.00 & 0.46 & 4.88 & 0.97 \\
\hline
\end{tabular}

\section{Conclusions}

The considerations of former points show the inherent uncertainty in the "physical" (wave generation/propagation) and statistical characterization of wave conditions along Mediterranean coasts.

The torrential-like climate of the Catalan Spanish coast limits the predictability of operational forecasts and precludes a "narrow" statistical estimation.

The performed research combining numerical simulations, field observations and statistical analyses suggest a nesting sequence (using WAM and an energetic wave propagation model) which, as discussed in previous points, considers the topo-bathymetric gradients for the aspect ratio of the various grids. The existence of land-wind and double peaked spectra further reduce the accuracy of wave forecasts. The same applies to the short duration storm events typical of the Mediterranean coast.

This limited predictability also affects the statistical characterization of wave parameters. The available data series (all shorter than 25 years) along the Spanish Mediterranean coast require the supplement of hind-casted fields to obtain robust statistical estimates, particularly for extreme events. In this context the use of semi-quantitative a priori "information" allows using a Bayesian approach which has proved to be more realistic and reliable than conventional probabilistic techniques.

All these considerations imply that due care should be taken when presenting forecasted fields or when recommending statistical estimators. The level of uncertainty should always be considered for the subsequent decision process.

Acknowledgements. The authors want to acknowledge the CIRCE (Climate Change and Impact Research: The Mediterranean Environment, TST5-CT-2007-036961, http://www.circeproject.eu), FLOODsite (Global Change and Ecosystems: Integrated Flood Risk Analysis and Management Methodologies, GOCE-CT-2004505420, http://www.floodsite.net) and MARIE (Modelling and Assimilation for RofI Environments. Limits of Predictability, MTKD-CT-2004-014509) European projects. This research has also been partially supported by the RIMA (Hacia una reducción de riesgos marítimos usando modelado de alta resolución, MEC, 
TRA2006-05132/TMAR) project. The authors want also to acknowledge the effort of all those involved in the field data collection and statistical analyses. The support of the Catalan Meteorological Service (E. Vilaclara, J. Cunillera and A. Sairouni) is also duly acknowledged.

Edited by: F. Guzzetti

Reviewed by: L. Cavaleri and another anonymous referee

\section{References}

Battjes, J. A. and Janssen, J. P. F. M.: Energy loss and set-up due to breaking of random waves, Proc. 16th Int. Conf. Coastal Engineering, Hamburg, 569-587, ASCE, New Cork, 1978.

Bolaños, R. and Sáchez-Arcilla, A.: A Note on Nearshore Wave Features. Implications for Wave Generation, Prog. Oceanogr., 70, 168-180, 2006.

Bolaños, R., Jorda, G., Cateura, J., Lopez, J., Puigdefabregas, J., Gómez, J., and Espino, M.: The XIOM: 20 years of a regional coastal observatory in the Spanish Catalan coast, J. Marine Syst., accepted, 2008

Bolaños, R., Rotes, A., and Sánchez-Arcilla, A.: Spectral wave climate at northern spain's Mediterranean coast, The Fifth International Symposium on Ocean wave measurement and analysis, Madrid, Spain, 3-7 July 2005.

Bolaños, R., Sánchez-Arcilla, A., and Cateura, J.: Evaluation of two atmospheric models for wind-wave modelling in the NW Mediterranean, J. Marine Syst., 65, 336-353, 2007.

Bolaños, R., Sánchez-Arcilla, A., Gómez, J., Cateura, J., and Sairouni, A.: Limits of operational wave prediction in the Northwestern Mediterranean, International Conference on Coastal Engineering, Lisbon, Portugal, September, 2004.

Bolaños, R., Sánchez-Arcilla, A., Gómez, J., Vilaclara, E., and Sairouni, A.: Prediccion de sucesos extremos en la costa Catalana, VII Jornadas Españolas de Ingenieria de Costas y Puertos, Almeria, 22-23 May 2003.

Cavaleri, L. and Bertotti, L.: Accuracy of the modelled wind and wave fields in enclosed seas, Tellus, 56a, 167-175, 2004.

Cavaleri, L. and Bertotti, L.: The characteristics of wind and wave fields modelled with different resolutions, Q. J. Roy. Meteor. Soc., 129, 1647-1662, 2003.

Codina, B., Aran, M., Young, S., and Redaño, A.: Prediction of a mesoescale convective system over the Catalonia (North-eastern Spain) with a nested numerical model, Meteorol. Atmos. Phys. 62, 9-22, 1997.

Dally, W. R., Dean, R. G., and Dalrymple, R. A.: Wave height variation across beaches of arbitrary profile, J. Geophys. Res., 90(C6), 11917-11927, 1985.

Del Amo, P. A. A.: Aspectos de la variabilidad de mesoescala de la circulación marina en la plataforma continental catalana, $\mathrm{PhD}$ thesis, Universidad Politécnica de Cataluña, 425 pp., 2000.

Donelan, M. A.: The effect of swell on the growth of wind waves, Johns Hopkins APL, Technical Digest, 8(1), 18-23, 1987.

Ebersole, B. A.: Refraction-diffraction model for linear water waves, J. Waterw. Port C.-ASCE, 111(6), 939-953, 1985.

Egozcue, J. J. and Tolosana-Delgado, R.: BGPE: Bayesian Generalised Pareto Estimation v2.0 CD program and documentation, edited by: Diaz, J. L., ISBN 84-699-9912-5, Universitat Politècnica de Catalunya, Barcelona, Spain, 2002.
García, M. A., Sánchez-Arcilla, A., Sierra, J. P., Sospedra, J., and Gómez, J.: Wind waves off the Ebre Delta, NW Mediterranean, J. Marine Syst., 4, 235-262, 1993.

Gómez Aguar, J., Espino, M., Sánchez-Arcilla, A., Solano, M., and Vela, J.: Extreme wave conditions in a torrential climate, The Catalan case, Ocean Wave Measurement and Analysis, Proceedings of the Fifth International Symposium WAVES, CD-ROM, 2005.

González-Marco, D., Sánchez-Arcilla, A., Bolaños, R., Sospedra, J., Sierra, J. P., and Uzcanga, J.: Forecasting wave conditions in beaches, From nested simulations to field observations, Proc. 29th Int. Conf. Coastal Engineering, ASCE, Lisbon, v1, 791803, 2004

González-Marco, D., Bolaños, R., Alsina, J., and Sánchez-Arcilla, A.: Implications of nearshore processes on the long term $\mathrm{Hs}$ probability distribution, J. Hydraul. Res., 46, 2, 303-313, 2008.

Grémare, A., Amouroux, J. M., Cauwet, G., Charles, F., Courties, C., De Bovee, F., Dinet, A., Devenon, J. L., Madron, X. D., Ferre, B., Fraunie, P., Joux, F., Lantoine, F., Lebaron, P., Naudin, J. J., Palanques, A., Pujo-pay, M., and Zudaire, L.: The effects of a strong winter storm on physical and biological variables at the shelf site in the Mediterranean, Oceanol. Acta, 26(4), 407-419, 2003.

Komen, G. J., Cavaleri, L., Donelan, M., Hasselmann, K., Hasselmann, S., and Janssen, P. A. M.: Dynamics and Modelling of Ocean Waves, Cambridge University Press, 532 pp., 1994.

Liu, P. L. F.: Wave transformation, The Sea, 9, 27-63, WileyInterscience, New York, 1990.

Madsen, O. S.: Spectral wave-current bottom boundary layer flows, Proc. 24th Int. Conf. Coastal Engineering, Kobe, 384-398, ASCE, Japan, 1994

Madsen, O. S., Poon, Y. K., and Graber, H. C.: Spectral wave attenuation by bottom friction: Theory. Proc. 21st Int. Conf. Coastal Engineering, Malaga, 492-504, ASCE, Reston VA, 1988.

Martín-Vide, J. and Olcina, J.: Climas y Tiempos de España, Alianza editorial, España, 2001.

MESO: MASS version 5.6 Reference Manual, MESO, Inc., 185 Jordan Rd., Troy, NY, 118 pp., 1994

Mitsuyasu, H., Tasai, F., Suhara, T., Mizuno, S., Ohkusu, M., Honda, T., and Rikiishi, K.: Observations of the directional spectrum of ocean waves using a cloverleaf buoy, J. Phys. Oceanogr., 5(4), 750-760, 1975.

Mitsuyasu, H. and Yoshida, Y.: Air-sea interactions under the existence of swell propagating against the wind, Bull. Res. Inst. Appl. Mech., Kyushu Univ., 63, 47-71, 1989.

Monbaliu, J., Padilla Hernández, R., Hargreaves, J., Carretero, J. C., Weimin, L., Sclavo, M., and Gunther, H.: The spectral wave model, WAM adapted for applications with high spatial resolution, Coast. Eng., 41, 41-62, 2000.

Nielsen, P.: Coastal bottom boundary layers and sediment transport, Advances Series on Ocean Engineering, 4, World Scientific Publishing, Singapore, 1992.

Puertos del Estado: Maritime Works Recommendations. ROM 0.391 Waves Annex 1: Wave Climate on the Spanish coast. Anejo I p. 76. Ministerio de Obras Publicas y Transporte, Centro de Publicaciones de Secretaría General Técnica, 1994.

Puig, P., Palanques, A., and Guillen, J.: Near-bottom suspended sediment variability caused by storms and near-inertial waves on the Ebre mid continental shelf (NW Mediterranean), Mar. Geol., 
178, 81-93, 2001.

Sánchez-Arcilla, A., Espino, M., Bolaños, R., Gómez, J., Jorda, G., Ponce de Leon, S., and Sairouni, A.: Wave and current forecasting along the Spanish Catalan coast. in Building the European capacity in operational oceanography, Proceedings of the EUROGOOS conference, 379-385, 2002.

Skliris, N., Lacroix, G., and Djenidi, S.: Effects of extreme meteorological conditions on coastal dynamics near a submarine canyon, Cont. Shelf Res., 24, 1033-1045, 2004.
Tolman, H. L.: An evaluation of expressions for wave energy dissipation due to bottom friction in the presence of currents, Coast. Eng., 16, 165-179, 1992.

Wallén, C. C.: Climates of Northern and Western Europe (World survey of climatology), 5, Elsevier, Amsterdam, 1970.

WAMDI Group: The WAM model - A third generation ocean wave prediction model., J. Phys. Oceanogr., 18, 1775-1810, 1988. 